\title{
Complutum
}

ISSN: 1131-6993

\section{Las estatuas-menhir noroccidentales: cronologías y conexiones materiales}

\author{
Javier Rodríguez Corral ${ }^{1}$
}

Recibido 07 de octubre de 2016 / Aceptado: 22 de junio de 2018.

Resumen. Este artículo analiza la cronología de las estatuas-menhir que se distribuyen en el área noroccidental de la península Ibérica. Aunque el grupo principal de estas formas materiales ha sido datado tradicionalmente en el Bronce Final, algunos arqueólogos han retrasado sus fechas al Bronce Inicial y Medio. El propósito de este trabajo es contribuir al debate sobre su contexto cultural y temporal, tomando en consideración las conexiones materiales entre las estatuasmenhir (a través de proceso de encadenamiento), y de sus iconografías con referentes reales y otras formas materiales (a través de procesos de anclaje).

Palabras clave: Estatua-menhir; estela; Bronce Tardío; Bronce Final; cronología; conectividad; Noroeste de Iberia.

\section{[en] North-western Statues-menhir: chronologies and material connections}

Abstract. This paper deals with the chronology of the statues-menhir located in northwestern Iberia. While the main group of these material forms has been traditionally dated to the Late Bronze Age, some archaeologists in recent years have considered they date back to the Early and Middle Bronze Age. The aim is to contribute to the debate about their cultural and temporal context, taking into consideration the material connections between theses statues-menhir (by means of enchainment processes), and between their iconographies, real references and other material forms (by means of anchoring processes).

Key words: Statue-menhir; stelae; Late Bronze Age; chronology; connectivity; the Northwest of Iberia.

Sumario: 1. Introducción. 2. Algunos problemas en los argumentos cronológicos. 3. Las estatuas-menhir con representación de armas en el norte de Portugal. 4. Otras estatuas-menhir con representación de armas: Valdefuentes, Tremedal y Preixana 5. Las estatuas-menhir de Ataúdes y Cruz de Cepos. 6. Estatuas-menhir sin armas. 7. Conclusiones

Cómo citar: Rodríguez Corral, J. (2018): Las estatuas-menhir noroccidentales: cronologías y conexiones materiales. Complutum, 29(1): 37-57.

\section{Introducción}

Las estatuas-menhir conforman una categoría no totalmente homogénea de imágenes materiales características de la región atlántica de la península Ibérica. Se trata de un grupo de monolitos de tendencia antropomorfa con un programa iconográfico centrado en las armas y la vestimenta, y que tienen como elemento más definitorio el denominado emblema sub-rec- tangular. Su área de dispersión abarca la zona comprendida entre los valles de los ríos Duero y Miño, con especial incidencia en la planicie del río Támega, y las actuales regiones de Tras-os-Montes, la Beira Alta y la provincia de Salamanca (fig. 1). Fuera de esta área, el monumento de Preixana, considerado también una estatua-menhir, se localiza excéntricamente en el noreste peninsular. 


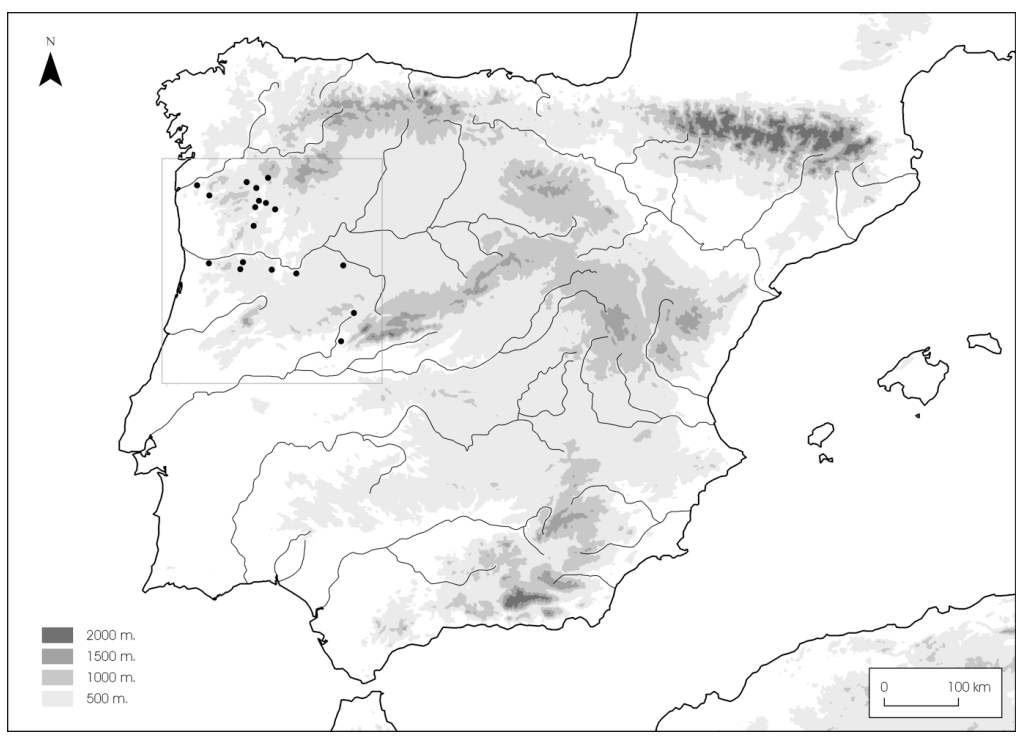

Figura 1. Mapa de distribución de las estatuas-menhir

Siguiendo las propuestas de Jorge y Jorge (1990), estos monumentos han sido tradicionalmente adscritos al Bronce Final (Almeida y Jorge 1979; Jorge y Almeida, 1980; Sanches y Jorge 1987; Barceló 1989: 257; Sanches 1995; Cardoso 2002: 396; Bettencourt 2005; Fábrega et al. 2011), planteándose en algún caso cronolo- gías más antiguas que retrotraen algún ejemplar, incluso, al Neolítico Final. Con todo, un giro reciente en las propuestas cronológicas ha empezado a considerar estas estatuas-menhir como formas materiales del Bronce Inicial/Medio (Vilaça et al. 2001; Díaz-Guardamino 2010; Alves y Reis 2011; Cruz y Santos 2011) (fig. 2).

\begin{tabular}{|c|c|c|c|}
\hline Estatua-menhir & Localización & Cronología & Bibliografía \\
\hline \multirow[t]{3}{*}{ Chaves } & Vila Real & Bronce Final & Jorge y Jorge 1990, 1993 \\
\hline & & Bronce Final & Bettencourt 2005 \\
\hline & & Bronce Inicial y Pleno & Díaz-Guardamino 2010 \\
\hline \multirow[t]{2}{*}{ São João de Ver } & Aveiro & Bronce Final & Jorge y Jorge 1990, 1993 \\
\hline & & Primera Edad del Hierro & Queiroga 2003 \\
\hline \multirow[t]{5}{*}{ Faiōes } & Vila Real & Bronce Final & Barceló 1989 \\
\hline & & Bronce Final & Jorge and Jorge 1990 \\
\hline & & Bronce Pleno & Bueno 1990 \\
\hline & & Bronce Final & Bettencourt 2005 \\
\hline & & Bronce Inicial y Medio & Díaz-Guardamino 2010 \\
\hline \multirow[t]{2}{*}{ Longroiva } & Tras-os-Montes & Bronce Inicial & Jorge y Jorge 1990, 1993 \\
\hline & & Bronce Inicial & Díaz-Guardamino 2010 \\
\hline \multirow[t]{2}{*}{ Valdefuentes } & Salamanca & Bronce Pleno & López et al. 1996 \\
\hline & & Bronce Inicial & Díaz-Guardamino 2010 \\
\hline \multirow[t]{2}{*}{ Tremedal } & Salamanca & Bronce Pleno o Bronce Final & López et al. 1996 \\
\hline & & Bronce Inicial & Díaz-Guardamino 2010 \\
\hline \multirow[t]{4}{*}{ Preixana } & Lleida & Final B. Medio/inicios B. Final & Almagro Bash 1974 \\
\hline & & $\begin{array}{l}\text { Bronce Pleno } \\
\end{array}$ & Bueno 1990 \\
\hline & & Bronce Pleno & Barceló 1989 \\
\hline & & Bronce Inicial/Bronce Pleno & Díaz-Guardamino 2010 \\
\hline \multirow[t]{2}{*}{ Ataúdes } & Guarda & B. Antiguo/transición B. Medio & Vilaça et al. 2001 \\
\hline & & B. Inicial/inicio Bronce Medio & Díaz-Guardamino 2010 \\
\hline Cruz de Cepos & Vila Real & B. Antiguo/transición B. Medio & Alves y Reis 2011 \\
\hline Marco & Tras-os-Montes & Bronce Final & Jorge y Jorge 1990, 1993 \\
\hline \multirow[t]{2}{*}{ Alto de Escrita } & Viseu & Calcolítico Final, B. Inicial o Medio & Carvalho et al. 1999 \\
\hline & & Bronce Inicial y Pleno & Díaz-Guardamino 2010 \\
\hline \multirow[t]{2}{*}{ Millarón } & Cáceres & Neolítico/Calcolítico & Bueno et al. 2004 \\
\hline & & Bronce Inicial y Pleno & Díaz-Guardamino 2010 \\
\hline \multirow[t]{6}{*}{ Ermida } & V. do Castelo & Calcolítico Final/Bronce Inicial & Baptista 1985,1995 \\
\hline & & Bronce Final & Barceló 1989 \\
\hline & & Bronce Final & Jorge y Jorge 1990 \\
\hline & & Bronce Antiguo/Medio & Almagro-Gorbea 1994 \\
\hline & & Bronce Final & Bettencourt 2005 \\
\hline & & Bronce Inicial y Pleno & Díaz-Guardamino 2010 \\
\hline \multirow[t]{3}{*}{ Boulhosa } & V. do Castelo & Neolítico Final/Calcolítico & Jorge y Jorge 1990, 1993 \\
\hline & & Bronce Antiguo/Medio & Almagro-Gorbea 1994 \\
\hline & & Bronce Inicial y Pleno & Díaz-Guardamino 2010 \\
\hline \multirow[t]{2}{*}{ Bouça } & Bragança & Bronce Final & Jorge y Jorge 1990, 1993 \\
\hline & & Bronce Inicial y Pleno & Díaz-Guardamino 2010 \\
\hline Tameirón & Ourense & Bronce Tardio/Final & Comendador et al. 2011 \\
\hline \multirow[t]{2}{*}{ Muiño de San Pedro } & Ourense & Bronce Final & Jorge y Jorge 1990, 1993 \\
\hline & & Bronce Final & Barceló 1989 \\
\hline \multirow[t]{2}{*}{ Nave 1} & Viseu & Bronce Antiguo y Medio & Cruz y Santos 2011 \\
\hline & & Bronce Inicial y Pleno & Díaz-Guardamino 2010 \\
\hline \multirow[t]{2}{*}{ Nave 2} & Viseu & Bronce Antiguo y Medio & Cruz y Santos 2011 \\
\hline & & Bronce Inicial y Pleno & Díaz-Guardamino 2010 \\
\hline San $M a$ & Castelo Branco & Bronce Inicial y Pleno & Díaz-Guardamino 2010 \\
\hline
\end{tabular}

Figura 2. Las estatuas-menhir y sus cronologías 
A pesar de que los datos disponibles son escasos y poco concluyentes, este nuevo encuadre cronológico (Bronce Inicial/Medio), lejos de suponer una propuesta alternativa dentro del debate cronológico, se ha instalado como un discurso en cierto modo hegemónico frente a otras opciones. En la mayoría de los casos, esta nueva cronología ha sido planteada dentro de estudios cuyo principal propósito era dar a conocer un nuevo ejemplar. $\mathrm{Si}$ exceptuamos el trabajo de Díaz-Guardamino (2010), carecemos de estudios que aborden el análisis actualizado y sistemático del encuadre temporal de estos monumentos en su conjunto. El propósito de este artículo es resolver dicho problema contribuyendo al debate sobre las estatuas-menhir noroccidentales.

Para ello, se examinan las conexiones materiales entre las estatuas-menhir y sus propias iconografías, así como entre estas y otras formas materiales (estelas del suroeste, estelas alentejanas, etc.) y diferentes referentes del registro arqueológico. Dicha aproximación permite, por un lado, matizar o constatar inconsistencias en algunos de los argumentos que respaldan el giro cronológico y, por otro, plantear un conjunto de posibles relaciones materiales e iconográficas que permiten señalar el periodo final de la Edad del Bronce como un contexto de acción de las estatuas-menhir. En esta línea, se plantea la necesidad de matizar tanto aquellas propuestas tradicionales que las sitúan estrictamente en el Bronce Final como aquellas que tienden a considerarlas un fenómeno del Bronce Inicial o inicios del Bronce Medio, proponiendo en su lugar una tercera vía que considere el periodo del Bronce Tardío/Final (1400/1200-900/850 cal. a.C. véase Díaz-Guardamino, 2010: 53) como el contexto fundamental de estos monumentos; sin obviar que este fenómeno pueda hundir sus raíces en momentos previos.

\section{Algunos problemas en los argumentos cronológicos}

La ausencia de información estratigráfica y dataciones absolutas ha dificultado el encuadre cronológico de las estatuas-menhir. Actualmente, la única alternativa para superar este problema radica en establecer conexiones materiales de dos tipos: anclajes externos y encadenamientos internos. En el primer caso, se trata de asociaciones entre los grabados de las estatuas-menhir y sus posibles referentes materiales (p. ej. con una espada real), o iconografías de otras formas materiales (p. ej. con la representada de una espada en una estela alentejana). En el segundo caso, las asociaciones formales o iconográficas se establecen dentro de la misma categoría de las estatuas-menhir (p. ej. entre las armas o los motivos sub-rectangulares que en ellas se graban).

El primer tipo de paralelo (conexión externa) permite un efecto de anclaje cronológico fuera de la categoría. Al asociar su iconografía con artefactos o representaciones de artefactos documentados en otras formas materiales, dichos paralelos pueden aportan información cronológica esencial. Por ejemplo, la asociación entre la espada representada en el ejemplar de Valdefuentes y la espada $n^{\circ} 1$ del depósito de Guadalajara - considerada su referente real-suministra a muchos autores un elemento externo con el que datar la estatua-menhir. En el segundo tipo de paralelo (conexión interna), el isomorfismo entre elementos presentes en dos o más estatuas-menhir produce un efecto de encadenamiento dentro de la categoría. Esto permite vincular diferentes estatuas-menhir a través de sus elementos iconográficos, y si alguna de ellas aporta algún dato cronológico -derivado de una asociación externa con un referente material o icónico-, este se puede extender a las restantes. Por ejemplo, la similitud formal entre las espadas representadas en Valdefuentes y Tremedal ha permitido generalizar la fecha de anclaje de aquella a esta última (López et al. 1997). En otras ocasiones, la extensión de una cronología dentro de la categoría de estatuas-menhir se hace de modo más genérico. Es el caso de la propuesta de datación de Cruz de Cepos, que fue establecida en concordancia con algunas fechas planteadas para estatuas-menhir como Tremedal o Ataúdes, sobre la base de que comparten la representación de armas y del motivo sub-rectangular (Alves y Reis 2011: 177).

Este modelo de análisis que combina conexiones externas e internas resulta útil para estudiar un registro arqueológico como el de las estatuas-menhir que, por el momento, no ha aportado información estratigráfica relevante. Sin embargo, al mismo tiempo, presenta problemas difícilmente eludibles: mientras el efecto de anclaje puede introducir errores, el efecto de encadenamiento los puede generalizar al conjunto de los monolitos. En este sentido, la primera y más obvia dificultad radica en 
saber si el paralelo ha sido establecido correctamente. Aunque en algunos casos los referentes son aceptados sin discusión (p. ej. la alabarda tipo Carrapatas representada en Longroiva), en otros casos existen discrepancias. Este es el caso del arma documentada en Ataúdes, que ha sido interpretada dependiendo del autor como una espada larga (Vilaça et al. 2001) o corta (Díaz-Guardamino 2010), lo que abre el camino a diferentes propuestas cronológicas. Otra dificultad en la interpretación, al igual que ocurre con las iconografías de las estelas del suroeste, radica en el posible origen exógeno de los referentes materiales de los iconos. Es el caso, por ejemplo, de los semicírculos concéntricos representados sobre el pecho de las estatuas-menhir asociados en ocasiones a gargantillas del Bronce Inicial de la región atlántica a pesar de que sus mejores paralelos, como veremos, pueda que se localicen fuera del área de dispersión de las estatuas-menhir.

El problema, otras veces, se centra no tanto en la propuesta, sino en la recepción historiográfica de la misma que, a través de los procesos de encadenamiento, minimiza los matices y precauciones señaladas por los autores que publicaron o estudiaron las piezas. Se ha subrayado, por ejemplo, la necesidad de asumir "con reservas" las conclusiones que sustentan el encuadre del ejemplar de Chaves en el Bronce Final (Jorge y Jorge 1990: 309), o el componente "aleatorio" de las observaciones que permiten datar la estatua-menhir de Tremedal en el Bronce Pleno (López et al. 1996: 301). El estudio de Cruz de Cepos (Alves y Reis 2011) se apoya precisamente en la cronología propuesta para el monumento de Tremedal, señalando como una "posibilidad" la datación del monolito en el Bronce Antiguo-transición al Bronce Medio. Sin embargo, frecuentemente, a través de la inter-cita, estos matices se diluyen en el contexto global de análisis de las estatuas-menhir, ayudando a retroalimentar y consolidar en cada momento determinadas propuestas cronologías como seguras.

Esta tendencia hace que a veces asumamos algunas cronologías como ciertas, dotándolas incluso con la capacidad de corregir la cronologías de aquellos objetos que en principio funcionaban como referentes materiales para datar las propias estatuas-menhir. En este sentido, propuestas recientes que defienden dataciones para las estatuas-menhir en torno al Bronce Inicial y Medio han sido usadas para envejecer la cronología de los referentes mate- riales propuestos para sus grabados, sin aclarar la razón que permite sostener tal datación. Al usarse una lógica circular en este tipo de planteamientos, las cronologías de los referentes materiales solo son válidas si remiten al Bronce Inicial/Medio; en caso contrario deben ser corregidas o revisadas. Este problema puede ilustrarse a través dos ejemplos. El enmangue de la espada $n^{\circ} 1$ del depósito de Guadalajara es uno de ellos. Esta pieza, utilizada por los autores como referente material de las empuñaduras de espadas grabadas en estelas alentejanas y estatuas-menhir, ha sido encuadrada en el Bronce Tardío/Bronce Final (1400-1150 cal. a.C.). Se sabe que substituyó a la empuñadura original (Bronce Pleno) y que, por tanto, la hoja en la que se engarza es anterior. Esto ha permitido concluir a los autores que la estudiaron que este tipo de hoja se siguió utilizando a finales de la Edad del Bronce (Almagro-Gorbea 1972; Brandherm 1998). Sin embargo, Díaz-Guardamino (2010: 305-306, $315)$, aunque acepta este argumento en otra parte, cuando aborda específicamente las estatuas-menhir sostiene que empuñaduras como la del depósito de Guadalajara debieron ser típicas del período anterior al estar representadas en Ataúdes y Valdefuentes.

Un argumento similar lo volvemos a encontrar en el análisis que esta autora hace del isomorfismo de las espadas grabadas en la estatua-menhir de Ataúdes y en la estela alentejana de Mouriços. Esta última se incluye en el subtipo C de Gomes, con una cronología entre 1300/1200 y 1100 a.C. (Gomes 1994: 131). Si se acepta la seriación de este autor, el paralelo podría servir como anclaje cronológico para la espada de Ataúdes. Sin embargo, en la propuesta de Díaz-Guardamino (2010: 165, 169), es la estatua-menhir de Ataúdes la que termina datando la estela de Mouriços, sosteniendo que hay que revisar su cronología "a la alta". Ataúdes le sirve, incluso, para datar el formato 1 de la estalas alentejanas que sitúa a partir del 2000 cal. a.C., sin quedar tampoco claro el argumento que permite defender tal datación. Asimismo, la estela de Mouriços apareció en contexto arqueológico, a diferencia del monolito de Ataúdes.

Estos argumentos, en definitiva, parecen funcionar dentro de una lógica que asume el envejecimiento de las estatuas-menhir como algo plenamente demostrado, anulando incluso las posibles fechas tardías que aportan los referentes materiales o paralelos icónicos 
para estas formas materiales. De este modo, invirtiéndose el proceso de razonamiento que a priori siempre se defiende (los referentes metálicos son la mejor forma para datar este tipo de monumentos), las estatuas-menhir pasan a operar como anclajes cronológicos para artefactos (la espada $\mathrm{n}^{\mathrm{o}} 1$ de Guadalajara) y otras representaciones materiales (la estela de Mouriços).

Por otro lado, a pesar de que los autores consideran que las armas metálicas son el referente más fiable para datar los monolitos, estas están también sujetas a debates cronológicos donde los datos y las asociaciones contextuales se entretejen aportando fechas y seriaciones que están lejos de ser seguras. Asimismo, existe otra cuestión no menos importante: saber qué están datando realmente las armas cuando éstas se consideran referentes materiales de los iconos representados en las estatuas-menhir. La cronología de un artefacto no sirve para fechar acríticamente el momento en que fue grabado y, mucho menos, por extensión el contexto de acción del monolito. En todo caso, señala la antigüedad máxima del tipo objetual que se representa en la estatua-menhir. Es decir, si asumimos que el icono se realizó cuando se erigió la estatua-menhir (lo que no siempre ha de ser así), su referente real permite saber que la estatua-menhir no puede ser anterior a la fecha post quem de ese tipo de objeto, pero esto no implica que los grabados y el monolito deban datarse en dicho momento.

El registro arqueológico en la región atlántica peninsular revela que el depósito y la representación de un artefacto son acciones que muestran a menudo lógicas temporales diferentes. Objetos como tranchets o ponderales aportan cronologías más antiguas en contextos de depósito que en la iconografía de las estelas de guerrero, lo que indica que su representación pudo retrasarse en el tiempo, como ha señalado Díaz-Guardamino (2010: 352). La misma circunstancia se constata entre las alabardas tipo Montejicar y su representación en estelas alentejanas: mientras este arma aporta cronologías antiguas en contextos de depósito (Bronce Inicial/Medio), su representación en las estelas alentejanas (p. ej. Assento) suministra cronologías recientes (Bronce Tardío/ Bronce Final). Estamos ante un caso, por tanto, donde una fecha post quem de un depósito estaría envejeciendo la cronología de las representaciones. Este ejemplo es especialmente oportuno, si tenemos en cuenta que los autores asumen la presencia de este tipo de alabarda en la estatua-menhir de Valdefuentes.

Cuando los artefactos se utilizan como referentes de los grabados, se debe tener en cuenta sus biografías, reconociendo el carácter multi-temporal tanto de los depósitos como de las representaciones. En esta línea, Olivier (1999) criticó hace tiempo la idea de depósito cerrado utilizado por la crono-tipología tradicional. Con este concepto, se asume que los diversos objetos de un depósito (ritual, funerario, etc.) tienen la misma cronología y fueron colocados simultáneamente y que, por tanto, el registro arqueológico suministra una imagen sincrónica de un momento en la historia de las entidades culturales estudiadas por los arqueólogos. Sin embargo, como el autor afirma, los objetos filtran diferentes temporalidades relacionadas con los individuos, el uso y la naturaleza del depósito.

Estas consideraciones son extensibles a las estatuas-menhir. Sus programas iconográficos materializan al menos dos temporalidades: (1) una filtrada por la propia biografía de los objetos o tipos objetuales grabados en su superficie y (2) otra creada por la historia de los diferentes contextos de elaboración y uso de la estatua-menhir. En el primer caso, los objetos que se representan definen la biografía del personaje de la estatua-menhir. Diferentes formas de conectividad socio-material (herencias, intercambios, pactos, relaciones de reciprocidad, etc.) pueden reunir objetos antiguos y exógenos al contexto inmediato del personaje que son decisivos en la construcción de su identidad. En el segundo caso, tenemos que asumir el carácter procesual de los grabados; es decir, la biografía de las estatuas-menhir. De hecho, un análisis detenido de las mismas confirma que en ocasiones las iconografías fueron reactualizadas añadiéndose nuevos elementos.

Por consiguiente, debemos tener en cuenta dos circunstancias. En primer lugar, la asignación a un estatua-menhir de las dataciones o fechas post quem de los referentes materiales de objetos representados en ella puede tener un efecto de envejecimiento injustificado al suministrar fechas que no tiene que ver con la creación y uso del monolito, sino con la genealogía y las temporalidades que filtra la biografía de la persona que se representa y que se fija a través de los objetos grabados. Y en segundo lugar, debido al carácter diacrónico de algunas de estas iconografías, los grabados también pueden pertenecer a diferentes momentos de la vida de 
los monolitos fruto de su reutilización o uso continuado. Por tanto, el elemento con mayor antigüedad no puede generalizar su cronología acríticamente al resto de la iconografía, mientras que el elemento más reciente sí suministra una fecha ante quem. En este último caso, sin embargo, dicha fecha puede estar datando tan solo una fase (una reactualización) en la creación de una iconografía que puede ser diacrónica. En suma, no debemos obviar que, tal como ha señalado Galán (2000), los grabados de armas u otro tipo de objetos, por su carácter simbólico, son difíciles de datar mediante las fechas convencionales de sus referentes.

Tomando en consideración la problemática que acabamos de señalar, se analizan en los siguientes apartados diferentes conexiones materiales a través de procesos de anclaje y encadenamiento. Esta contextualización permite no solo matizar las propuestas que consideran las estatuas-menhir un fenómeno del Bronce inicial, sino proponer otras posibles que permiten defender el Bronce Tardío/Final como un un contexto de acción fundamental de dichas formas materiales.

\section{Las estatuas-menhir con representación de armas en el norte de Portugal}

Dentro del grupo más noroccidentales -se analizan en otro apartado los monumentos de Ataúdes y Cruz de Cepos-, la estatua-menhir de Chaves es quizá la que más información aporta al debate cronológico. A pesar de que se ha datado tradicionalmente en el Bronce Final (Jorge y Almeida 1980; Barceló 1989: 287-288; Betterncourt 2005), dicha atribución ha sido contestada por otros autores que la sitúan bien en el Bronce Medio (Baptista 1995: 28), bien en el Bronce Pleno o Bronce Inicial (Díaz-Guardamino 2010: 175). Sin embargo, las propuestas que defienden las cronologías más antiguas han recurrido a criterios asociativos poco concluyentes. Díaz-Guardamino, por ejemplo, sin dar más explicaciones, afirma que la asociación de un puñal y una espada en el monolito de Chaves remite "a cronologías similares, aunque un poco más recientes" (2010: 173) que aquellas que propone la autora para las estatua-menhir de Longroiva o las estelas de Tabuyo de Monte o Peña Tú, y que data en el Bronce Inicial. Asimismo, en otro lugar, sin precisar más, señala que "a la luz de las grafías que ofrecen las diversas estatuas-menhir" (2010: 177), el ejemplar de Chaves puede ser atribuido genéricamente al Bronce Inicial y Pleno.

Lo cierto es que el programa iconográfico de Chaves no muestra ningún elemento común con las iconografías de las estelas tipo Peña Tú o con estatuas-menhir como Longroiva que nos permita establecer un anclaje externo o un encadenamiento interno, respectivamente. Por el contrario, conexiones iconográficas ineludibles pueden ser constituidas con algunas estelas de guerrero o alentejanas. El mejor ejemplo lo aporta la espada/ puñal presente en uno de los laterales (cara 4) de Chaves, que tiene sus mejores paralelos en la iconografía de un grupo específico de estelas de guerrero de tipo básico (fig. 3). Tanto en estas estelas como en Chaves se documentan espadas de diferente longitud pero igual tipología, con empuñadura recta y filo ancho. Al margen de la cronología genérica asumida para las estelas de guerrero en el Bronce Final, el análisis tipológico de dichas armas aporta información clave para ubicar la estatua-menhir (fig. 3.4). En primer lugar, cabe notar que la dispersión de estos ejemplares se localiza en el sector septentrional del área de distribución de las estelas de suroeste (Beira Baixa, Beira Alta, Badajoz y Cáceres); por tanto, su localización las pone en relación directa con el grupo de estatuas-menhir noroccidentales. En segundo lugar, la morfología de estas espadas difiere de los modelos más característicos del Bronce Final (pistiliformes o de lengua de carpa), por lo que resultan muy útiles para afinar la cronología del arma figurada en la estatua-menhir que nos ocupa. 


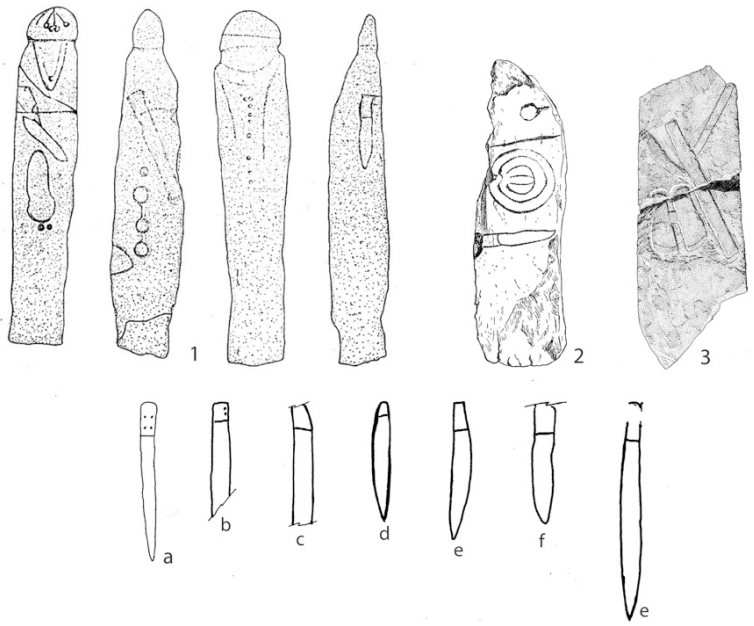

Figura 3. 1. Chaves (Jorge y Jorge 1990); 2. Tres Arroyos (Celestino 2001); 3. Gomes Aires (Almagro Gorbea 1966). 4. Espadas representadas en estelas del suroeste (Brandherm 2007): a. Eiras; b y d. El Manjar de los Puercos, c. Salvatierra de Santiago; e. El Oreganal I; f. Tres Arroyos; g. Los Herraderos

La espada de la estela de Cabeza Gorda -la que dentro de este grupo más se diferencia a la grabada en Chaves- se representa con una hoja triangular que la aleja de las espadas canónicas del Bronce Final. Brandherm (2007: 148), encuentra su paralelo más próximo en el tipo Montefrío, y la integra en su Clase K, que se extiende desde un momento final del Bronce Medio hasta el Bronce Tardío. Una de las espadas de Torrejón el Rubio IV, la de Salvatierra de Santiago y la de Eiras, entran dentro de la Clase A (Brandherm 2007: 134), datándose en los inicios del Bronce Final. Por lo que se refiere a las espadas documentadas en la otra estela de Torrejón el Rubio IV, Oreganal I, y Tres Arroyos (fig. 3.2), con la que el icono de Chaves guarda una isomorfismo pleno (Jorge y Almeida 1980; Barceló 1989: 257), todas presentan hojas cortas y ensanchadas y enmangues de perfil recto. Estos ejemplares se enmarcan en la Clase B (Brandherm 2007: 136), que es posterior a la Clase A.

Tomando en consideración la distribución septentrional de estas estelas de guerrero y la tipología de sus espadas, se pueden plantear dos posibilidades: o bien se trata de estelas propias del Bronce Tardío/Final, o bien durante el Bronce Final se representaron espadas arcaizantes en un área compartida por estelas de guerrero y estatuas-menhir. Pervivencias de este tipo no son extrañas en el registro arqueológico de este periodo, constatándose, por ejemplo, en el depósito de la Ría de Huelva (Brandherm 2007: 25). El paralelismo formal con este conjunto de representaciones y el iso- morfismo pleno con el grabado de la estela de Tres Arroyos nos lleva a datar con bastante seguridad el icono de Chaves en el inicio del Bronce Final.

Por otro lado, la figura alargada y rectangular que se representa en la cara 2 de la estatua-menhir permite establecer una conexión con la iconografía de la estela alentejana de Gomes Aires (Almagro Basch 1966: 120), en donde aparece esta misma figura pendiendo del cinturón (fig. 3.3). Este último monumento ha aparecido junto a una estela del suroeste con escritura y ha sido datado en el Bronce Tardío/ Bronce Final (Díaz-Guardamino 2010: 322). Así, la conexión icónica de Chaves con esta estela alentejana remiten al mismo horizonte cronológico que acabamos de señalar para la espada/puñal.

A tenor de la técnica de ejecución, Jorge y Almeida (1980: 9-11) han señalado dos posibles momentos en la elaboración de la iconografía de Chaves. De acuerdo con dichos autores, en una fase se grabó una espada y un puñal en el lado izquierdo y derecho del monolito (caras 1 y 4) y, en otra, se representó el motivo sub-rectangular y la espada envainada que pende del cinturón representado esquemáticamente (caras 2 y 3 ). Esta propuesta permite establecer un paralelo con el ejemplar de Torrejón el Rubio IV (Celestino 2001: 333), donde se documenta el mismo número y tipo de armas que en la estatua-menhir de Chaves. Ambas iconografías permiten una correlación entre sus elementos: la estela del guerrero presenta un arma (tal vez un puñal), 
como la que aparece en la cara 1 de Chaves; una espada envainada con forma rectangular, como en la cara 2 de Chaves; y, superpuesta a ésta, otra espada que guarda isomorfismo con la representada en la cara 4 de la estatua-menhir y el resto de estelas de guerrero antes mencionadas.

Se han propuesto también dos fases en la elaboración de la iconografía de la estela, ya que la espada, que se asemeja a la representada en la cara 4 de Chaves, se superpone a la espada envainada. Por tanto, se podría plantear como hipótesis que se grabaran inicialmente las caras 2 y 3 (emblema y espada envainada), y posteriormente las caras 1 y 4 (la espada y el puñal). Sea como fuere, de ser correcta la propuesta que defiende dos momentos en la elaboración de Chaves, ambas fases no se distanciarían demasiado en el tiempo. El grabado del mismo elemento alargado y rectangular en Gomes Aires, Torrejón y Chaves remite al Bronce tardío/Bronce Final. Por tanto, no debemos descuidar el hecho de que el uso compartido de iconos entre las estatuas-menhir, las estelas de guerrero y las estelas alentejanas está remitiendo a contextos de acción comunes o vinculados a ese periodo para todas estas formas materiales.
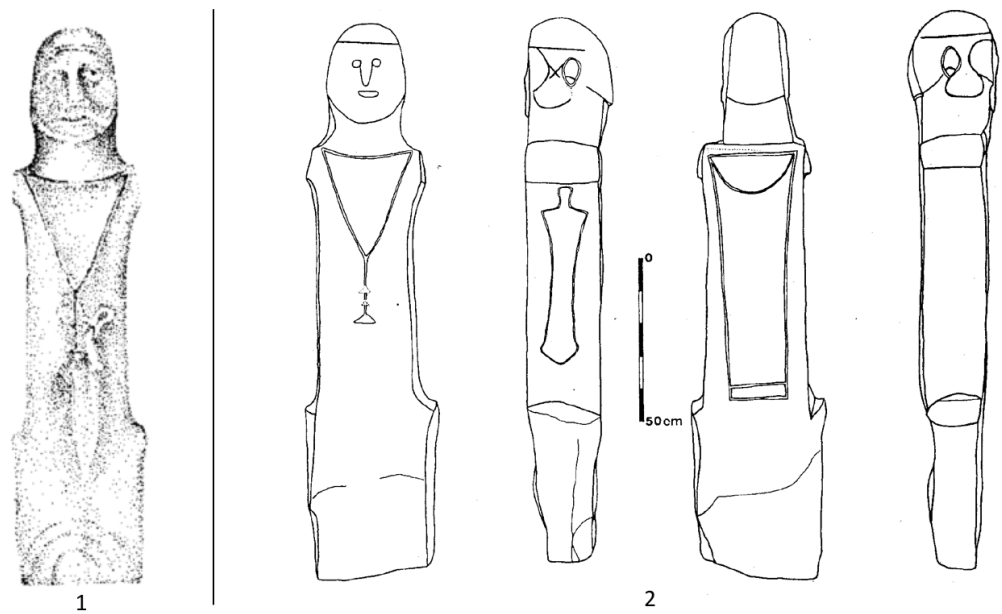

Figura 4. Estatua-menhir de São João de Ver: 1. Según Silva (2007); 2. Según Jorge y Jorge (1990)

La estatua-menhir de São João de Ver, por su morfología e iconografía, se ha datado en las postrimerías del Bronce Final y, especialmente, en la primera Edad del Hierro (Jorge y Jorge 1990; Queiroga 2003: 85). El argumento principal que sustenta esta cronología se centra en el casco en bulto redondo que ha sido vinculado a modelos mediterráneos de inicios de la Edad del Hierro. Recientemente, Silva (2007) ha realizado un nuevo levantamiento de este monumento, incorporando más elementos al conjunto de grabados (fig. 4). De acuerdo con este autor, se representan tres círculos concéntricos en la parte baja del monolito, que interpreta como un escudo, y una figura en la zona central que considera la representación de un puñal de antenas. Por lo demás, São João de Ver, junto a las estatuas-menhir de Ermida y Muiño de San Pedro, se diferencian del resto de ejemplares por su rostro bien aislado y la representación de orejas, lo que según
Díaz-Guardamino (2010: 138) podría también indicar una fecha tardía. Con todo, Baptista (1985) planteó hace tiempo la posibilidad de que estos rasgos pudiesen haber sido añadido posterior.

La estatua-menhir de Faiões (fig. 5) ha sido datada en el Bronce Final (Almeida y Jorge 1979), Bronce Pleno (Bueno 1990) y, más recientemente, dentro de marcos temporales amplios, 2200/2000-1500/1400/1200 cal. a.C. (Díaz-Guardamino 2010: 174). En el primer caso, el criterio utilizado fue su proximidad geográfica con la estatua de Chaves. En el segundo caso, su asimilación a estatuas-menhir corsas e italianas. En el tercer caso, fue asociada a través de un proceso de encadenamiento a otras estatuas-menhir con las que comparte el motivo sub-rectangular.

El intento de retrotraer su cronología hasta finales del tercer milenio a.C. carece de evidencia arqueológica, justificándose tan solo 
a partir del argumento que asocia este monumento al de Longroiva por compartir ambos el motivo sub-rectangular. En primer lugar, también lo comparte con las estatuas-menhir que acabamos de ver y no remiten a esta cronología. En segundo lugar, mientras que Longroiva es la estatua-menhir de aspecto más arcaico, la de Faiões muestras una apariencia mucho más tardía. En tercer lugar, como tendremos ocasión de ver, la iconografía de Longroiva parece ser diacrónica, pudiendo haber sido el motivo subrectangular un añadido posterior.

Por otro lado, un argumento utilizado para datarla en el Bronce Inicial se apoya en el paralelo establecido entre los círculos concéntricos representados en el pecho de la estatua-menhir y las gargantillas de tiras datadas en torno al 1700-1550 a.C. que se documentan en depósitos de la región atlántica (Díaz-Guardamino 2010: 242). Sin embargo, dicho paralelo plantea también tres problemas. En primer lugar, los círculos concéntricos son de difícil interpretación y no solo han sido considerados collares, sino también pliegues de un vestido (Vilaça et al. 2001: 76). En segundo lugar, en el caso de ser interpretados como collares múltiples, resulta injustificado que se obvien otros posibles paralelos que podrían resultar más adecuados. Es el caso, por ejemplo, del collar múltiple de Sintra datado en el Bronce Final (Armbruster 1995). Mientras que las gargantillas localizadas en depósitos fueron diseñadas para ser ajustadas al cuello del individuo, en las estatuas-menhir los círculos concéntricos se representan sobre el pecho, funcionando más como pectorales o collares. Y, en tercer lugar, los círculos concéntricos representados bajo el cuello - que serán tratados con más detenimiento al abordar las estatuas-menhir de Nave 2-, son un elemento recurrente en una serie de estelas que remiten a cronologías del Bronce Tardío/Final. Por tanto, a la hora de encontrar un paralelo para este motivo, no existe razón para decantarse por las gargantillas y obviar estos referentes materiales e icónicos cuya disposición en el cuerpo encajan mejor con los motivos representados en las estatuas-menhir.

Por otro lado, si se admite la premisa de que en Faiões se representa un collar múltiple y no los pliegues de un vestido, se debe asumir que el motivo sub-rectangular se grabó en el reverso de la estatua-menhir. Esta ubicación aleja a Faiões de ejemplares como el de Longroiva y la acerca a ejemplares como Chaves o São João de Ver cuyas cronologías remiten respectivamente al Bronce Tardío/Final y a la primera Edad del Hierro. En este sentido, el grabado del emblema en el reverso ha sido interpretado como un rasgo propio de monumentos tardíos (Jorge y Jorge 1993: 41). Las posibles conexiones entre estos tres monolitos no se agotan aquí. En primer lugar, la cercanía geográfica entre ellos podría reforzar su vinculación y, en segundo lugar, el arma representada en Faiões, aunque ejecutada con escaso detalle, encuentra su mejor paralelo dentro de la categoría de las estatuas-menhir en la espada documentada en São João de Ver. En ambos casos, se representan con la misma empuñadura, envainadas y con las conteras desarrolladas y sujetas al cinturón en uno de sus laterales.

Por tanto, aunque no contamos con conexiones materiales para Faiões que permitan plantear con seguridad una cronología, tal como ocurre con los ejemplares Chaves y São João de Ver, a tenor de los datos, no parece justificado asignarle marcos temporales mucho más antiguos que los planteados para Chaves ni cerrar la posibilidad de un encuadre en el Bronce Tardío/Final.

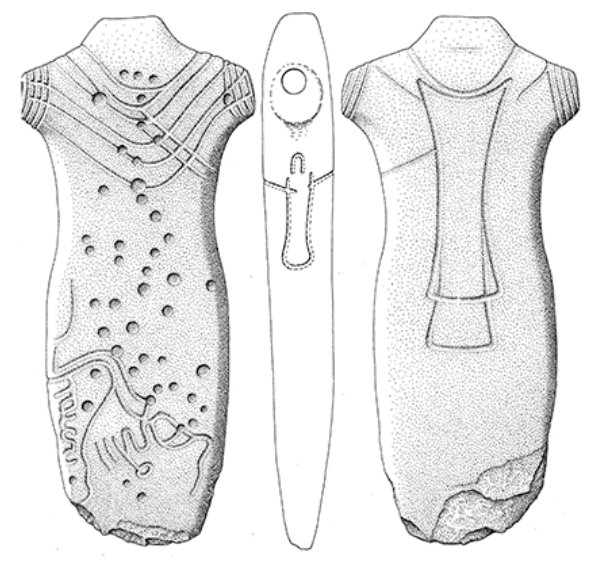

Figura 5. Faiões (Brandherm 2003) 
El monumento de Longroiva, por su forma y por el grabado únicamente de una de sus caras, se aproxima más a una estela que a una estatua-menhir (fig. 6.1). Aun así, la representación de rasgos antropomorfos y del motivo sub-rectangular permite incluirlo dentro del conjunto de estatuas-menhir noroccidentales. En el anverso, además del emblema, se representan un puñal, una alabarda y un arco. El esquematismo del puñal, aunque no ayuda a establecer paralelos con referentes reales, muestra isomorfismo

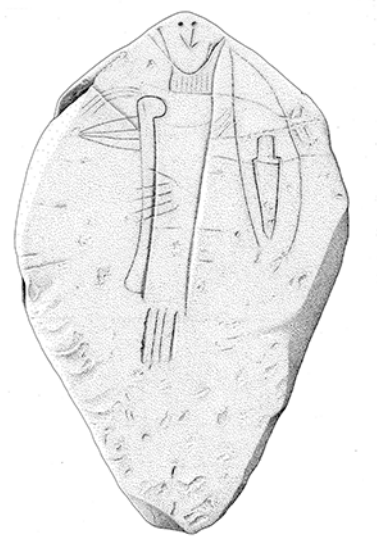

con puñales grabados en estelas del norte de la península Ibérica datados en el Bronce Inicial (Bueno 1990:107). Asimismo, se documenta una alabarda característica del ámbito atlántico (tipo Carrapatas) cuyos mejores referentes se encuentran en la propia región de Tras-os-Montes y se datan en el Bronce Inicial (Schuhmacher 2002) o Bronce Medio (Brandherm 2003). Por tanto, deberíamos situar la fecha post quem de los dos grabados dentro de estas dos propuestas (Jorge y Jorge 1990: 305).

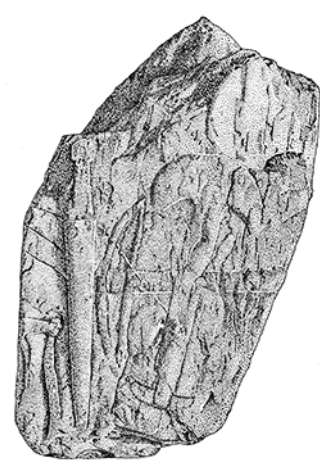

Figura 6. 1. Longroiva; 2. Santa Vitoria (Almagro Basch, 1966)

La representación del arco resulta más problemática. El grabado de este objeto parece remitir a finales de la Edad del Bronce. Los ejemplos más antiguos dentro de este periodo se documentan en las estelas alentejanas de Santa Vitoria y Assento, datadas en el Bronce Tardío/Final (fig. 6.2). En este sentido, ha sido señalada la concordancia y similitud entre la posición del arco dentro de las composiciones iconográficas de estas tres piezas (Díaz-Guardamino 2010: 307). No obstante, las estelas del suroeste son la forma material sobre la que se representan con más asiduidad este objeto, remitiendo al Bronce Final como el momento característico de estas representaciones $(\mathrm{Ce}-$ lestino 2001).

En función de los iconos, su composición y la técnica de grabado, el programa iconográfico de Longroiva, como Díaz-Guardamino ha señalado (2010: 136), parece ser diacrónico. E1 motivo sub-rectangular - de líneas más rectas que la mayoría de ejemplares- encuentra sus mejores paralelos en São João de Ver y Millarón (Bueno 1995: 112-113). Ambas piezas remiten a fechas tardías. En el lateral izquierdo del bloque de Millarón, se representan incisiones horizontales que recuerdan a las composiciones grabadas en Valdefuentes y Ataúdes, mientras que en una posición central, se documenta el emblema. Según esta autora, "por el lugar que ocupa este motivo rectangular y por la técnica en la que se realiza, diferente del resto, se puede decir que este motivo ha sido realizado en un momento posterior a la fractura del soporte y, por lo tanto, es posterior a los demás motivos" (Díaz-Guardamino 2010: 712). Es muy factible proponer, por tanto, que la alabarda y el puñal de Longroiva fueron grabados en el Bronce Inicial/Medio, mientras que en un momento posterior -durante el Bronce Tardío/Final- se grabó el motivo sub-rectangular -en función de los paralelos de Millarón y São João de Ver-, y el arco -sobre la base de los paralelos que se conocen sobre este tipo de armas.

\section{Otras estatuas-menhir con representación de armas: Valdefuentes, Tremedal y Preixana}

Los grabados de las estatuas-menhir que se analizan en este apartado han permitido establecer asociaciones con tipos y referentes materiales, así como con iconografías propias de las estelas del sur de Iberia. A pesar de ello, 
la definición de estas asociaciones formales y tipológicas no ha ayudado a generar consenso sobre la cronología de estos monumentos. Tomando como base, por ejemplo, iconos como la alabarda presente en Valdefuentes o el carácter argárico de las espadas que en ellos se representan, los autores han propuesto dos cronologías: bien en el Bronce Pleno (1700-1200 a.C.) (López et al. 1996), bien en el Bronce Inicial (2000/1800-1600/1500 a.C.) (Díaz-Guardamino 2010). Aunque estas propuestas plantean conexiones materiales de gran interés, pensamos que existen razones para defender que los referentes materiales e icónicos a los que recurren remiten a contextos más tardíos que sitúan dichas piezas a finales de la Edad del Bronce.

En primer lugar, las espadas representadas en Valdefuentes (Santonja y Santonja 1978: 20), Preixana (Maluquer 1971) y Tremedal (López et al. 1996: 297-301) han sido asimiladas al formato IIb de la tipología de Almagro-Gorbea cuya cronología varía dependiendo de los autores (fig. 7). De acuerdo con Almagro-Gorbea, los morfotipos se distribuyen en una seriación con un intervalo entre el 1450/1400-900 a.C. Díaz-Guardamino (2010: 165), por su parte, ha datado el tipo IIa entre 1800 y 1500 cal. a.C., mientras que Brandherm (2003: 366-370) ha situado el tipo II ( $a$ y b) en el Bronce Pleno (1700-1200 cal. a.C.), a través de asociaciones contextuales con otros objetos. Si tenemos en cuenta las diferentes propuestas y asumimos que en estas estatuas-menhir se grabaron espadas largas del tipo IIb, en principio, se deberían datar en algún momento de la segunda mitad del segundo milenio a.C.

En segundo lugar, como ya ha sido señalado, los enmangues representados en estatuas-menhir como Valdefuentes y Tremedal han sido asociados a la empuñadura de la espada $\mathrm{n}^{\circ} 1$ del depósito de Guadalajara (López et al. 1996; Díaz Guardamino 2010). Esta arma presenta una hoja catalogada por Almagro (1972) como un tipo IIb y una empuñadura en oro que sustituyó a la original. Gracias a las improntas conservadas en la espada, sabemos que la primera empuñadura estaba formada por una escotadura de doble herradura -elemento característico de las espadas del Bronce Pleno (1700-1200 cal. a.C.)
(Brandherm 1998)- y que fue sustituida por la actual en algún momento del Bronce Tardío/Final (1400-1150 a.C.). Tampoco se debe obviar que en la espada de Forca (Ourense), que tipológicamente corresponde al Bronce Final, se documentan las huellas de dos arcos de herradura enmarcados dentro de un arco mayor, quizá porque "en su día llegó a contar con dos empuñaduras distintas" (Gómez 2001: 12). Por tanto, se puede constatar a través de dichas espadas el uso de enmangues con herradura a principios del Bronce Final. $\mathrm{Si}$ asumimos como correctos estos intervalos, el contexto temporal más probable para la representación en las estatuas-menhir de enmangues como el documentando en el depósito de Guadalajara sería el Bronce Tardío; aunque tampoco se puede descartar, a través de las asociaciones señaladas, la posibilidad de que las hojas tipo IIb hayan pervivido al menos hasta el inicio del Bronce Final.

Finalmente, no está claro que el morfotipo al que se deban asimilar las espadas de estas estatuas-menhir sea el IIb, pudiendo ser del tipo IIc y IId, si tenemos en cuenta que se representan sin estrangulamiento en su parte proximal. Esta posibilidad estaría en consonancia con la idea planteada por Díaz-Guardamino (2010: 165) cuando afirma que se podrían estar representando en ambas estatuas-menhir estoques o rapiers. Este tipo de armas han sido datadas por diversos autores en un Bronce Tardío/Bronce Final. El ejemplar más antiguo de este tipo de estoque puede ser el de Fuente Álamo (1500 a.C.), seguido de la espada de Cea (1400-1300 a.C.) y ejemplares como los de Castro Bom, Palencia o Forca, de tipología del Bronce Final y representarían la tradición más evolucionada (1300-1100 a.C.) (Almagro 1972; Delibes et al. 1982: 162; Ruiz-Gálvez 1984: 243; Gómez 2001; Brandherm 2003). Además, en el depósito de la Ría de Huelva, se ha documentado una espada (Brandherm 2007: 29; n 6) que representa sin duda el ejemplar más antiguo de todos los amortizados, y que muestra la perduración de ejemplares antiguos durante el Bronce Final. Sintomáticamente, la hoja de la espada $n^{\circ} 1$ de Guadalajara forma parte de un depósito con otras dos espadas con filos recto tipo IIc (Brandharm 2003). 

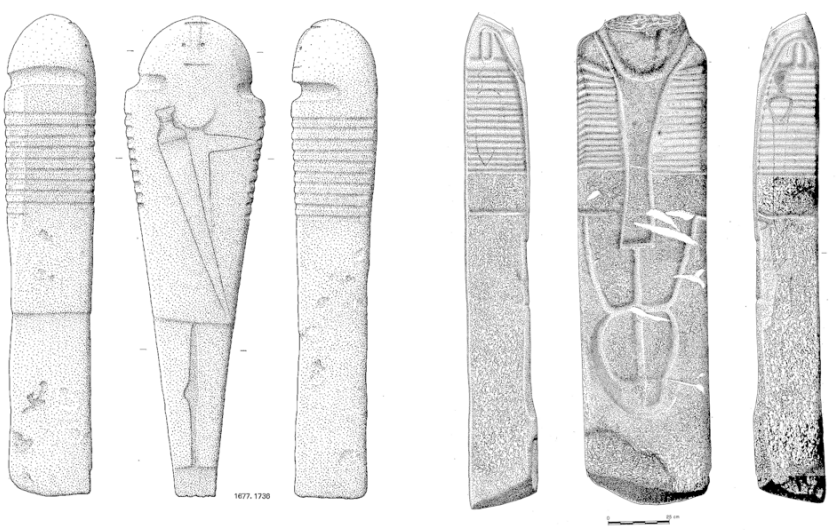

Figura 7. 1. Valdefuentes de Segura (Santonja y Santonja, 1978); 2. Tremedal de Tormes (López et al., 1996).

El otro elemento representado en la estatua-menhir de Valdefuentes es la alabarda. Su asimilación al tipo Montejicar ha servido para generalizar la cronología propuesta para los referentes de este modelo mediterráneo -que se datan en el 2000-1700/1600 cal. a.C.- a la estatua-menhir de Valdefuentes y, por extensión, a la de Tremedal (Díaz-Guardamino 2010: 193). Sin embargo, esta asociación presenta algún problema. Los contextos arqueológicos de estos objetos son en su mayoría dudosos, no suministran dataciones seguras, y sus asociaciones con otros objetos difieren de las documentadas en la iconografía de las estatuas-menhir y estelas alentejanas. Además, en este último caso, las alabardas y las espadas aparecen asociadas a hachas de enmangue directo que suministran una cronología de anclaje segura en el Bronce Tardío/Final, 14001200/1100 a.C. (Torres, 2008: 80; Díaz-Guardamino 2010: 303-304).

Si es correcta la asimilación de la albarda de Valdefuentes al tipo Montejicar, se constata para este artefacto una cronología de larga duración que Díaz-Guardamino (2010: 304) encuadra en el 2000/1800-1400/1200/1000 cal. a.C. Existen dos razones sustanciales para situar la representación de dicha alabarda en el Bronce Tardío/Final, y no en el Bronce Inicial, tal como se ha planteado. En primer lugar, los referentes a los que se recurre para datar las estatuas-menhir en el Bronce Inicial aparecen en los depósitos vinculados a puñales, mientras que las alabardas presentes en la estatua-menhir y en las estelas alentejanas se asocian con espadas. En segundo lugar, a través de las estelas alentejanas, la práctica de representación de este tipo de alabarda, y la acción socio-ma- terial que tal acto implica, solo se documenta en el Bronce Tardío/Final, y no antes. Por tanto, todo ello parece indicar que estamos ante lógicas asociativas y contextos temporales distintos.

Como ya hemos visto, los referentes materiales de los depósitos de Guadalajara y Abia de Obispalía permiten datar las empuñaduras representadas en las estatuas-menhir y estelas alentejanas en el Bronce Tardío/Final. Asimismo, los tipos de espada y alabarda representadas en las estatuas-menhir se documentan en las estelas alentejanas asociadas a hachas de enmangue directo que redundan en esta cronología. De este modo, el análisis de la alabar$\mathrm{da}$, las espadas y sus enmangues -recurriendo tanto a sus vinculaciones con referentes materiales como a la comparación con otras iconografías- aconsejan situar las iconografías de estas estatuas-menhir en el tramo final del arco cronológico que proponen López et al. (1996) para Tremedal y Valdefuentes, esto es, en un Bronce Tardío/Final.

Por otro lado, en el caso concreto del monumento de Preixana (Maluquer 1971), existen otras conexiones externas que abren la posibilidad de un análisis más allá de la mera comparación tipológica de su espada con aquellas documentadas en otras estatuas-menhir y estelas alentejanas. Por su iconografía y localización excéntrica en el noreste de Iberia, muestra una especificidad propia y diferenciada con el resto de estatuas-menhir. La interacción entre la iconografía y materialidad del monolito apuntan a una composición híbrida que no encaja perfectamente dentro de la categoría de las estatuas-menhir. Si atendemos a la representación en el anverso de un individuo con cabeza, 
cuello y brazos, y cuyo cuerpo adopta la forma del motivo sub-rectangular, la pieza de Preixana se aproxima al formato de una estela. $\mathrm{Si}$, por el contrario, nos centramos en el cinturón que rodea el monolito y la espada que pende en una de sus laterales, presenta una utilización del volumen propia de las estatuas-menhir. Por esta razón, dicha pieza parece materializar tanto rasgos de las estelas del sur como de las estatuas-menhir del noroeste.

En este sentido, los rasgos formales de Preixana permiten relacionarla con la estela de San Martinho III (fig. 8), donde se docu- menta la misma hibridación y esquema iconográfico: el cinturón se representa usando el monolito como materialización del cuerpo, al tiempo que este se usa como soporte para representar la misma figura humana con cuerpo sub-rectangular. En su parte inferior, la pieza portuguesa presenta una composición interpretada como un cinturón de remaches y un faldellín (Celestino 2001: 245), elementos que pudieron estar también presentes originalmente en Preixana, aunque no lo podemos saber porque la pieza se encuentra fracturada a esta altura.
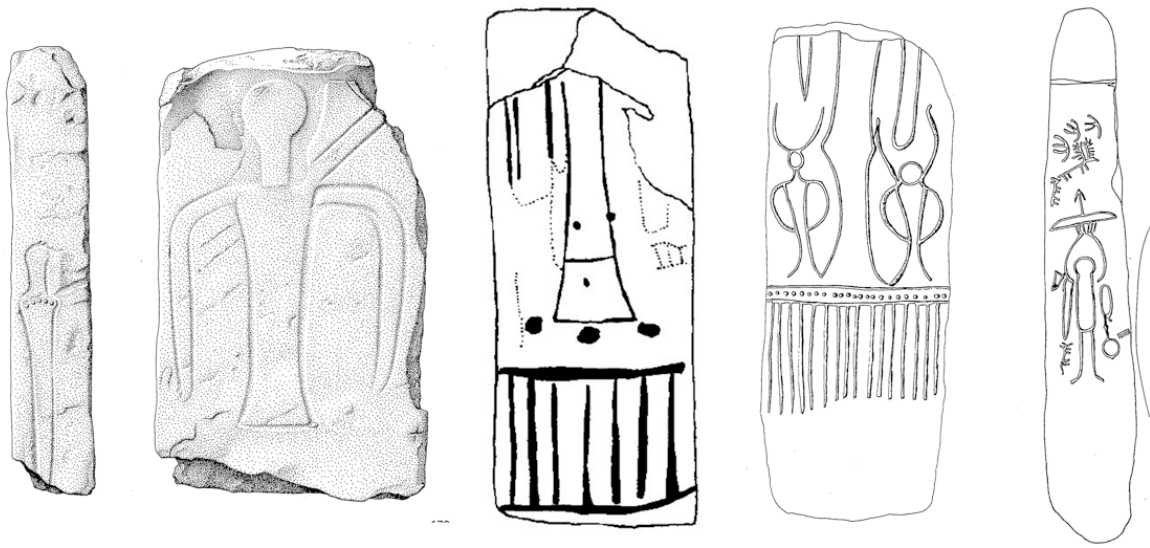

Figura 8. 1. Preixana (según Almagro Basch 1972); 2. San Martinho III (según Guardamino 2010); 3. San Martinho I; 4. San Martinho II (según Celestino 2001).

El isomorfismo entre ambas piezas aporta información sustancial para situar cronológicamente la pieza de Preixana. San Martinho III apareció junto a otros dos ejemplares (San Martinho I y II) en la ladera de una colina, junto a la muralla de un asentamiento del Bronce Final. En los ejemplares números I y II se grabaron elementos propios de un horizonte Bronce Final: en uno de ellos se representan dos individuos con cuernos; mientras que en el otro, se grabó una escena de caza, una fíbula de codo, un espejo y un peine. La representación del cinturón está asociada a la figura con rayas verticales y paralelas (faldellín), que tiene su correlato en otras estelas del suroeste con una datación segura en el Bronce Final, caso de Gomes Aires (Almodovar) (Celestino 2001: 445, $\mathrm{n}^{\circ}$ 88). Todo ello permite situar a San Martinho III y, por extensión -al poner en relación sus iconografíasa Preixana, en contextos socio-materiales del Bronce Tardío/Final.

\section{Las estatuas-menhir de Ataúdes y Cruz de Cepos}

Los estudios de Ataúdes y Cruz de Cepos son dos ejemplos que muestran cómo se generan en la investigación dinámicas que retroalimentan las tendencias dominantes en cada momento incluso aunque los datos que se manejan indiquen lo contrario.

En el primer caso, la estatua-menhir de Ataúdes (fig. 9.1) ha sido datada en el Bronce Antiguo/transición Bronce Medio (Vilaça et al. 2001) o en el Bronce Inicial/comienzos del Bronce Medio (Díaz-Guardamino 2010). Díaz-Guardamino (2010: 315) propone esta cronología al vincular la espada grabada en su superficie al tipo I de la seriación de Almagro. Aunque este tipo no tiene una cronología clara, recurre a los datos obtenidos de la espada de La Perla (Madrid) para su datación. El problema de esta asociación radica en que el arma de la estatua-menhir está envainada por lo que su hoja no se puede analizar según dicha tipología. Su asimilación al tipo I se establece, 
por tanto, únicamente al considerar que se trata de una espada corta, a pesar de que las dimensiones con los que se representó no permitan afirmarlo con seguridad. De hecho, los autores que publicaron la pieza (Vilaça et al. 2001), al contrario que Díaz-Guardamino, no dudan en incluirla dentro de las espadas largas tipo II que adscriben al Bronce Medio.
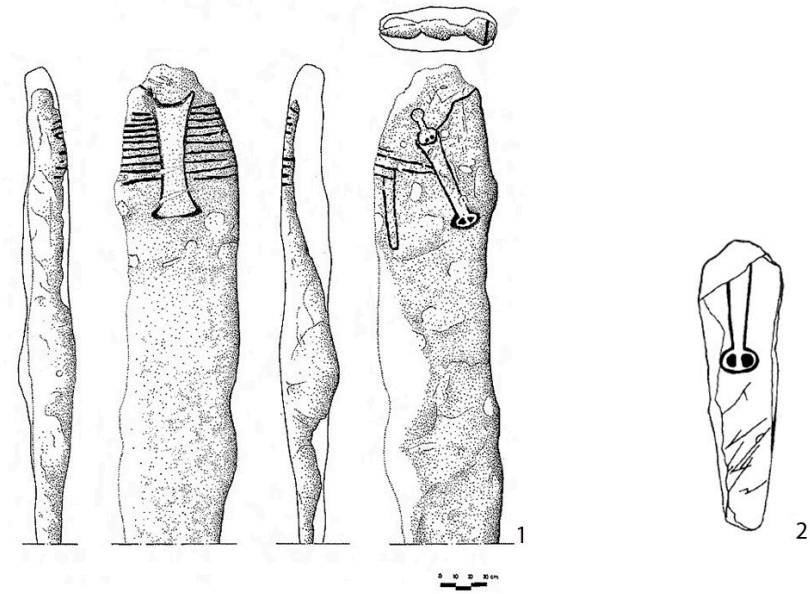

Figura 9. 1. Estatua-menhir de Ataúdes (Vilaça et al. 2001); 2. Estela alentejana de Mouriços (Guardamino 2010).

Se ha podido establecer también una conexión material entre la estatua-menhir de Ataúdes y la estela alentejana de Mouriços, ya que en ambos monumentos se representa exactamente la misma contera (fig. 9.2). Dicha estela se incluye en el subtipo $\mathrm{C}$ de Gomes y se data entre el 1300/1200 y el 1100 a.C. (Gomes 1994: 131). A pesar de que Vilaça at al. (2001) mencionan esta asociación y la cronología que aporta (Bronce Tardío/Final), no explican por qué prescinden de ella en su propuesta final. Por su parte, Díaz-Guardamino (2010: 169), al abordar esta conexión iconográfica, invierte la lógica asociativa, afirmado que a tenor del parecido entre ambas, la cronología de Mouriços "debería revisarse a la alta". Lo cierto es que Ataúdes no aporta información que permita datar la estela de Mouriços que, a diferencia de lo que ocurre con la estatua-menhir, ha aparecido en contexto arqueológico. Asimismo, resulta llamativo que ambos trabajos terminen situando en un mismo horizonte cronológico -en torno al Bronce Inicial- la pieza de Ataúdes, cuando sus argumentos no solo son diferentes sino contrarios. Mientras Vilaça et al. (2001) asimila la espada al tipo II que data en el Bronce Medio y considera el paralelo con la estela de Mouriços (Bronce Tardío/Final), Díaz-Guardamino asimila la espada al tipo I y, usando una razonamiento circular, envejece la estela de Mouriços, dentándola a partir de la estela-menhir.

No existen, sin embargo, evidencias que justifiquen cronologías tan tempranas en detri- mento de otras más tardías. En primer lugar, la estela de Mouriços apareció en la necrópolis de la primera Edad del Hierro de Cerro dos Mouriços (Ourique), probablemente relacionada con un túmulo. Aunque es posible que la pieza estuviera reutilizada en este contexto, nada justifica que se quiera datar en un momento "a partir" del 2000 cal. a.C. como se ha propuesto. En segundo lugar, la asignación al tipo I o II no está clara y, sin la posible especificación del subtipo, la utilización de la seriación de Almagro resulta demasiado imprecisa y aleatoria. Dejando al margen por un momento este hecho, Vilaça et al. (2001: 79), que consideran la espada como el único elemento objetivo "que autoriza una aproximación cronológica", no explican por qué si ellos mismos la datan en el Bronce Medio, retrotraen la cronología de la estatua-menhir al Bronce Antiguo o transición al Bronce Medio. En tercer lugar, el grabado permite constatar el isomorfismo entre la empuñadura de la espada de Ataúdes y aquellas que se documentan junto a hachas de enmangue directo en las estelas alentejanas, así como su vinculación a referentes metálicos como los depósitos de Guadalajara y Abía de la Obispalía (Almagro 1974). Por lo tanto, siendo conscientes de la dificultad que entraña datar este tipo de monumentos, la evidencia parece remitir a un contexto de acción vinculado al periodo final de la Edad del Bronce.

Por su parte, en la estatua-menhir de Cruz de Cepos se representan escasos elementos que 
ayuden a esclarecer su contexto cronológico. Además de documentarse el motivo sub-rectangular característico de las estelas-menhir noroccidentales, se representa la hoja de una espada que ha perdido el detalle de su empuñadura. Alves y Reis (2011) sitúan esta estatua-menhir en torno al Bronce Antiguo/transición Bronce Medio al vincularla de modo genérico a otros monolitos con figuración de armas metálicas y motivo sub-rectangular. Concretamente, señalan piezas como Tremedal, Ataúdes y Soalar (Navarra). En nuestra opinión, estas asociaciones plantean varios problemas. En primer lugar, no existe razón para datar Cruz de Cepos a través de la pieza de Soalar, con la que en realidad no comparte motivo sub-rectangular, iconografía, ni ésta se adscribe al grupo de estatuas-menhir noroccidentales. En segundo lugar, como hemos visto, en los casos de Ataúdes y Tremedal no está tan claro que se pueda sostener cronologías tan antiguas, existiendo argumentos que remiten a contextos temporales más tardíos. Y en tercer lugar, dentro del conjunto de estatuas-menhir con representación de armas y emblema sub-rectangular, la asociación más lógica debería establecerse con la estatua-menhir de Chaves. Los propios autores que publican la pieza han constatado, tras realizar un examen comparativo y directo, el isomorfismo existente entre las espadas de Chaves y Cruz de Cepos (Alves y Reis 2011: 168). Cruz de Cepos, además, comparte paisaje con el monumento de Tojais, una estela básica de guerrero datada en el Bronce Final (Rodríguez-Corral 2015: 164). Aunque esta relación no es ni mucho menos concluyente, merece ser mencionada. Por tanto, no parece que existan argumentos que permitan defender una cronología del Bronce Inicial. La conexión con Chaves revela en todo caso fechas en torno al Bronce Tardío/Final.

\section{Estatuas-menhir sin armas}

En las estatuas-menhir de Marco (Lopes et al. 1994), Ermida, Boulhosa, Bouça (Jorge y Jorge 1990), Tameirón (Comendador et al. 2011), Nave 1 y Nave 2 (Domingos y Santos 2011) no se representan armas. El ejemplar de Marco (Vila Real) carece además de cualquier tipo de grabado sobre su superficie, por lo que su filiación a las estatuas-menhir noroccidentales se debe exclusivamente a su forma antropomorfa y a la ubicación que ocupa en el área nuclear de las mismas. En los monolitos de Bouça y Tameirón tan solo se documenta el emblema sub-rectangular, lo que asegura su vinculación a este conjunto, sin que por lo demás aporten información cronológica. En las estatuas-menhir de Ermida, Boulhosa, Nave 1 y Nave 2, a pesar de la ausencia de armas, se representan rasgos faciales y elementos propios de la vestimenta -collares múltiples, cinturones, posibles tocados o corazas- y, en alguno de ellos, el motivo sub-rectangular.

Los autores que han publicado estas piezas se decantan por cronologías diferentes. Por lo que respecta a las estatuas-menhir del primer grupo (sin armas y elementos decorativos), las fechas propuestas responden a criterios exógenos a las mismas. Estos monumentos han sido generalmente situados en la segunda mitad del segundo milenio a.C. y, más concretamente, en el Bronce Final (Jorge y Jorge 1990; Batata et al. 2008: 163; Comendador et al. 2011). Esta cronología es coherente con la propuesta de Díaz-Guardamino (2010: 172) que plantea situar este tipo de estatuas-menhir (con emblema y sin armas) en momentos más tardíos que el resto de estas piezas.

Las dataciones propuestas para el resto de estatuas-menhir defienden momentos más antiguos (Jorge y Jorge, 1990; Bueno et al. 2005; Cruz y Santos 2011). Ermida y Boulhosa, que presentan rasgos comunes, han sido datadas en el Calcolítico, en el Bronce Inicial y en el Bronce Medio, aunque su esquematismo no aporta información relevante para su datación. Aun así, nuevamente, algunos argumentos permiten matizar dichas propuestas aportando encuadres cronológicos alternativos al debate. La representación de la cara y las orejas de Ermida se puede paralelizar con los rostros presentes en Muiño de San Pedro y São João de Ver, pudiendo interpretarse, según Díaz-Guardamino (2010: 138), como un rasgo tardío. Aun así, mientras que la sincronía de los grabados parece clara en São João de Ver, para esta autora podría tratase de un añadido posterior en el caso de Muiño de San Pedro, debido a su reutilización en el periodo romano.

En la pieza de Boulhosa se documenta una composición de semicírculos concéntricos. Su interpretación como un pectoral/collar múltiple permite vincularla con piezas como Nave 2, Faiões o Alto da Escrita (Carvalho et al. 1999). De ser así, el paralelo con estas estatuas-menhir sería el elemento más importante para datar el ejemplar. Por otro lado, el anverso de la esta- 
tua-menhir de Ermida presenta decoración en espina de pez, lo que ha servido para vincular este tipo de monumentos con el arte rupestre del Noroeste y un tradición que se remonta al Neolítico (Baptista 1985: 36-37). Este esquema decorativo, sin embargo, es característico de contextos del Bronce Tardío/Bronce Final (fig. 10): se constata en estelas del suroeste como Ategua; en abundantes depósitos y soportes metálicos del Bronce Final atlántico; y en cerámicas de Cogotas I (Abarquero 2005), por señalar tan solo algunos ejemplos.

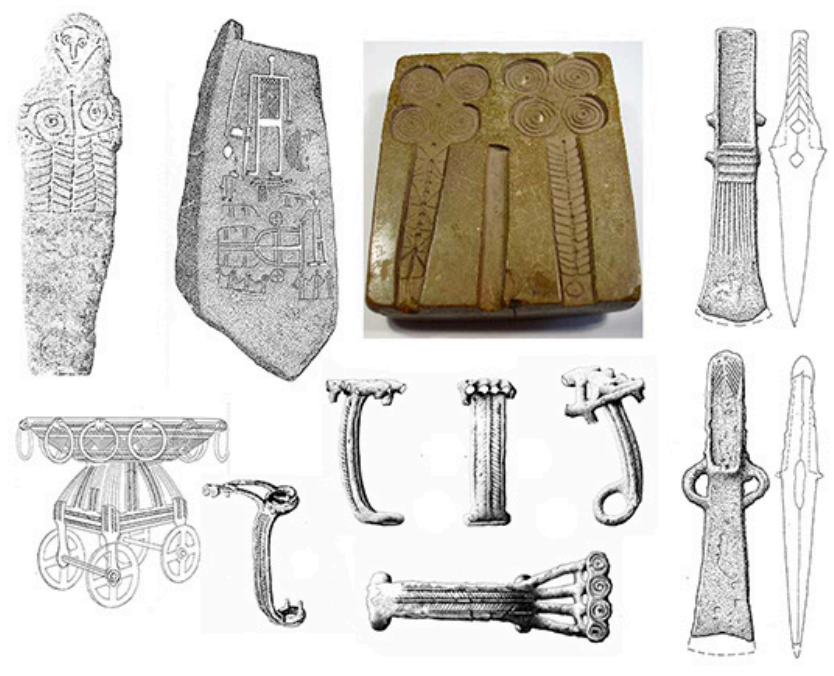

Figura 10. Estatua-menhir de Ermida y el motivo de "espina de pez" en el Bronce Final: 1. Ermida (Jorge y Jorge, 1990); 2. Ategua, Córdoba (Almagro Basch 1966); 3. Campo Redondo, Gouveia (Vilaça 2004); 4. Nuestra Senhora de Gaia (Baiões, Viseu); 5. Monte Sa Idda, Cerdeña (Taramelli, 1921); 6. Monte São Martinho, Castelo Blanco (Vilaça, 2004); 7. Pé do Castelo, Beja (Lopes y Vilaça 1998); 8. San Simón da Costa, Lugo; 9. Bardaos, A Coruña (Monteagudo, 1977)

Por su parte, dos premisas han sido utilizadas para datar las piezas de Nave: se asume que son coetáneas y que el emblema sub-rectangular en una de ellas las vincula a las estatuas-menhir noroccidentales. Los autores que firman dicha propuesta consideran que en las estatuas-menhir los emblemas se representan junto a alabardas, puñales y otras armas que "permiten la definición de una cronología dentro, sobre todo, del Bronce Antiguo y Medio" (Cruz y Santos 2011: 128). Como hemos visto, existen argumentos para pensar que el grabado de estas armas remite fundamentalmente a un contexto del Bronce Tardío/Final. Además, la estatua-menhir de Nave 2, que también presenta este esquema en espina de pez, apunta cronologías tardías a través de diversas conexiones materiales fuera de las estatuas-menhir (asociaciones de anclaje) (fig. 11).

Este monumento se puede analizar correlacionando el motivo sub-rectangular con el cinturón de remaches y el collar múltiple. Los collares multiples de este tipo se documentan claramente en Nave 2, Faiões, Alto da Escrita $\mathrm{y}$, con algunas dudas, Boulhosa. Este tipo de figuración ha sido asociado por algún autor, como señalamos más arriba, a gargantillas de tiras que suministran una cronología del Bronce Inicial (Díaz-Guardamino 2010). Sin embargo, lo que se representa en estas estatuas-menhir no son gargantillas, sino pectorales, collares múltiples representados sobre el pecho de la estatua-menhir. Por tanto, son factibles otros paralelos. Entre ellos, por ejemplo, collares múltiples del ámbito del Mediterráneo occidental como los documentados en el mundo balear (1400/13001000 a.C.) (Delibes y Fernández-Miranda 1988: 122) o, también, en el propio ámbito atlántico, caso del collar de Sintra. Este último fue elaborado durante el Bronce Final a partir de torques fabricados con tecnología atlántica, unidos y decorados con tecnología mediterránea, lo que permitiría pensar, por tanto, que el uso de collares múltiples acontece en contextos de interacción con el Mediterráneo. Ambos paralelos muestran mayor isomorfismo que las gargantillas y permiten situar estas representaciones en un Bronce Tardío/Final. 


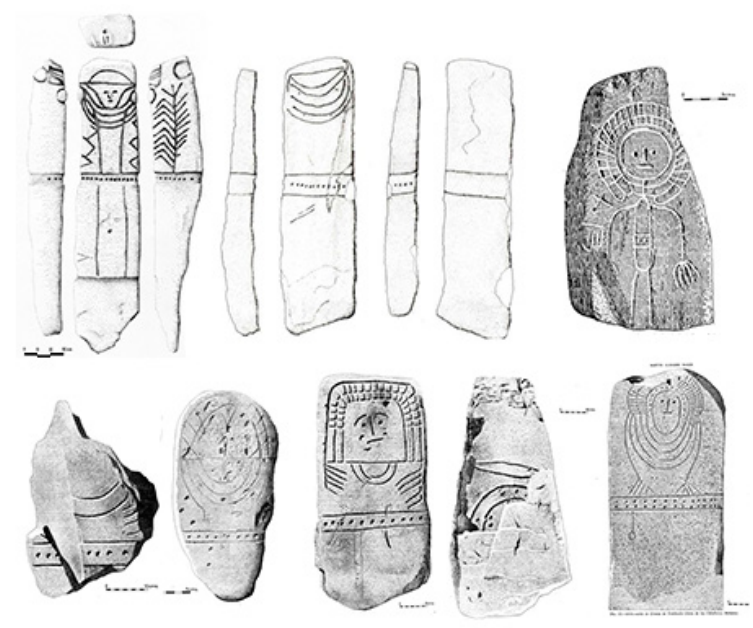

Figura 11. 1. Nave 2, Viseu (Cruz y Santos 2011); 2. Alto da Escrita, Viseu (Carvalho et al. 1999); 3. Torrejón el Rubio II, Cáceres; 4. Hernán Pérez III; 5. Hernán Pérez II; 6. Hernán Pérez VI; 7. Estela básica de guerrero, Cáceres; 8. La granja de Toniñuelo, Badajoz (Según Almagro Basch 1972).

En Nave 2 y Alto da Escrita, los collares múltiples se asocian a cinturones con remaches. Cinturones de este tipo se documentan en la tumba de Roca do Casal do Meio (Celestino 2001: 255) y en las iconografías de algunas estelas del suroeste y estelas-guijarro. Por lo que se refiere al primer tipo de estelas, estos dos elementos (cinturón y collar multiple) se asocian también a diademas, cuyos referentes reales remiten a una cronología del siglo XI a.C. (Celestino Pérez 2001: 253). Dos estelas de guerreros son especialmente interesantes en este punto. La estela de la Lentejuela (Oliva 1983; Berrocal 1987), que se considerada un ejemplar evolucionado dentro del Bronce Final, presenta una diadema junto al tipo de pectoral y cinturón que aparece en las estatuas-menhir. Por su parte, en la estela de Torrejón Rubio II se documenta una figura humana con diadema y cinturón de remaches. La iconografía la completan una fíbula de antenas y un peine, que revelan la misma cronología.

La estatua-menhir de Alto da Escrita, de gran similitud formal con Nave 2, muestra también gran parecido con las estelas-guijarro. La propuesta que en su día situó este tipo de piezas en el Calcolítico, argumentando su cercanía a monumentos funerarios y su relación a vías de comunicación, ha sido rechazada recientemente por diversos autores (Celestino 2001: 250-254; Santos 2009; Díaz-Guardamino 2010: 27-28). En primer lugar, las vías de comunicación natural no son exclusivas de un periodo concreto y, en segundo lugar, no se ha documentado vinculación directa entre espa- cios megalíticos y estelas-guijarro que permita defender fechas tan antiguas. Por el contrario, sí se documentan asociaciones contextuales entre estas estelas-guijarro y las estelas del suroeste en el conjunto coetáneo de Hernán Pérez (Celestino 2001; Santos 2009). La presencia de ambos tipos en un mismo contexto no solo permite comprobar su uso simultáneo y combinado durante el Bronce Tardío/Final, sino también verificar que el grabado de collares múltiples y cinturones de remaches, asociados en ocasiones a diademas, remiten a algún momento de este periodo. Así, resulta estos ejemplos resultan muy interesante para datar aquellas Estatuas-menhir en las que aparecen estos elementos.

Por último, el conjunto de estelas de San Martinho aporta información clave que redunda en la misma línea. Lo componen tres monolitos que se localizaron, como ya indicamos, junto a la parte exterior de la muralla de un asentamiento del Bronce Final. La zona donde se localiza el asentamiento y las estelas destaca además por la concentración de depósitos de hachas de talón y anillas. Si su localización remite a un contexto del Bronce Final, sus iconografías lo ratifican a través de diversos grabados: en San Martinho I, se representan dos antropomorfos con cuernos y en San Martinho II una fíbula de codo, un espejo y un peine, todos ellos característicos de este periodo. En dos de las estelas (San Martinho I y III) se documenta el cinturón con remaches y una figura interpretada como faldellín. Si en el primer caso, el cinturón se asocia a antropomorfos con 
cornamenta, en el segundo caso (San Martinho III) lo hace con el motivo sub-rectangular característico de las estatuas-menhir.

En suma, el conjunto de asociaciones contextuales que se pueden extraer de iconografías como las estelas de guerreros de la Lentejuela y Torrejón Rubio II, así como de los conjuntos de Hernán Pérez y San Martinho, son clave para contextualizar los motivos iconográficos de Faiões, Nave 2 y Alto da Escrita. En primer lugar, permiten vincular estas estelas a las estatuas-menhir, con las que comparten elementos iconográficos como los cinturones de remaches o los pectorales (collares múltiples). $\mathrm{Y}$ en segundo lugar, las asociaciones establecidas evidencian reiteradamente contextos del Bronce Tardío/Final.

\section{Conclusiones}

El propósito de este artículo ha sido mostrar como un análisis de las asociaciones externas e internas entre elementos iconográficos y contextuales aporta argumentos para defender que las estatuas-menhir fueron una socio-materialidad que tuvo, al menos, uno de sus contextos de acción en el Bronce Tardío/Final. Esto no significa que las biografías de estas formas materiales no se puedan retrotraer a un periodo anterior. No debemos obviar que la idea de "estatua-menhir" es una categorización arqueológica que tiende a homogeneizar un conjunto de formas materiales que en realidad muestran diferencias formales e icónicas. Basta comparar, por ejemplo, las piezas de Longroiva, Boulhosa, Faiões o Preixana para constatar este hecho que, entre otras razones, podría explicarse por la dispersión geográfica y temporal de los monolitos.

La alabarda y el puñal grabados en Longroiva pueden remitir perfectamente a un contexto del Bronce Inicial o Bronce Medio. Sin embargo, conviene no descuidar el hecho de que el elemento más antiguo dentro de una estructura doméstica, un depósito o una vestimenta no tiene por qué datar su fecha de creación o uso, ni todos los contextos en que funcionó. Además, como se ha expuesto, el resto de los elementos grabados en su superficie (emblema y arco) parecen remitir a un momento posterior, como otros autores han sostenido, por lo que este monolito podría estar filtrando diferentes momentos de uso. La estatua-menhir de Chaves -a través de sus conexiones iconográficas con estelas de guerrero y alentejanas- se debe datar ineludiblemente en el Bronce Tardío/Final; mientras que la de São João de Ver se fecharía en las postrimerías del Bronce Final o los inicios de la Edad del Hierro. Ambos monolitos permiten, además, llevar a cabo conexiones internas con otras estatuas-menhir. Los autores que han estudiado la pieza de Cruz de Cepos han puesto de relieve el isomorfismo entre la espada grabada en su superficie y la documentada en Chaves, lo que permite asignar a aquella la cronología contrastada de ésta. Cruz de Cepos también comparte, aunque sin relación contextual directa, paisaje con la estela de guerrero de Tojais (Bronce Final). Por otra parte, la morfología de los motivos sub-rectangulares de Longroiva y Millarón permite asociaciones con la estatua-menhir de São João de Ver, lo que hace pensar que esta tipología de emblema responde a momentos muy tardíos. En el caso de Longroiva, por tanto, remitiría a una fase más reciente que la de la alabarda y el puñal.

En las estatuas-menhir de Tremedal y Valdefuentes, las hojas y empuñaduras de las espadas parecen remitir a contextos del Bronce Tardío/Final, a través de sus asociaciones con referentes materiales (depósitos de Guadalajara y Abía de la Obispalía) y su asignación a morfotipos (rapiers o estoque) de la seriación de Almagro (1972). Asimismo, en Valdefuentes se documenta la misma alabarda que aparece representada en estelas alentejanas como Assento (asociadas a un hacha de enmangue directo) y que se datan con esa misma cronología. En otras estelas alentejanas las hachas de enmangue directo también se asocian a espadas como las que se documentan en estas estatuas-menhir. Ataúdes, por su parte, aporta dos datos de interés. En primer lugar, la empuñadura de la espada envainada que se representa en su superficie, al igual que en Tremedal, tiene su referente material en las empuñaduras de los depósitos de Guadalajara y Abía de la Obispalía datadas en el Bronce Tardío/Final; y, en segundo lugar, el isomorfismo con el grabado en la estela alentejana de Mouriços, redunda en esa misma cronología.

El esquema decorativo en espina de pez del monolito de Ermida y Nave 2 encuentra paralelos sistemáticos en contextos materiales del Bronce Tardío/Bronce Final. Ejemplares como Nave 2, Alto da Escrita o Faiões, con collares múltiples o cinturones, o con ambos elementos, permiten asociaciones claras con contextos y formas materiales (este- 
las-guijarro y estelas del suroeste) que, como hemos analizado, responden también a esta cronología. El monolito de Preixana muestra conexiones icónicas y formales claras con San Martinho III, lo que por su contexto de hallazgo -un asentamiento del Bronce Final-y por su asociación contextual con otras estelas -donde se representan antropomorfos con cornamenta, una fíbula de codo, un espejo, etc.- permite situar la pieza también en este periodo. Finalmente, por lo que respecta a las estatuas-menhir sin grabados o que solo documentan el emblema, el argumento esgrimido por algún autor como ya señalamos plantea que la ausencia o simplificación iconográfica puede remitir a formas materiales tardías, pero al margen de esta propuesta, este tipo de estatuas-menhir no aportan más información al debate cronológico.

En suma, mientras determinados argumentos que han sustentado el giro cronológico parecen inconsistentes, existen diversas conexiones materiales que remiten a finales de la Edad del Bronce. A la luz de lo esgrimido, y a la espera de que nuevos datos que aporten más información (nuevas conexiones materiales y, sobre todo, estratigrafías y dataciones absolutas), lejos de considerar estas estatuas-menhir una expresión escultórica del Bronce Inicial, parece apropiado defender el Bronce Tardío/ Final como un contexto de acción de esas formas materiales.

\section{Bibliografía}

Abarquero Moras, F. J. (2005): Cogotas I. La difusión de un tipo cerámico durante la Edad del Bronce. Valladolid: Junta de Castilla y León.

Almagro Basch, M. (1966): Las estelas decoradas del Suroeste Peninsular. Madrid: Consejo Superior de Investigaciones Científicas.

- (1974): "Nuevas estelas decoradas de la Península Ibérica". En Miscelánea Arqueológica. 25 Aniversario de los Cursos Internacionales de Prehistoria y Arqueología de Ampurias (1947-1971). Barcelona: Diputación Provincial: 5-39.

- (1972): "La espada de Guadalajara y sus paralelos peninsulares", Trabajos de Prehistoria, 29: 55-78.

- (1974): "Orfebrería del Bronce Final en la Península Ibérica. El tesoro de Abía de la Obispalía, la orfebrería tipo Villena y los cuencos de Axtroki", Trabajos de Prehistoria, 31: 39-100.

- (1994): "Las estelas antropomorfas en la Península Ibérica. Tipología, dispersión, cronología y significado". En La Statuaria Antropomorfa in Europa dal Neolitico alla Romanizzazione. La Spezia: Istituto Internayionale di Studio: 69-108.

Almeida, C.A.F. de y Jorge, V. O. (1979): “A estátua-menir de Faiões (Chaves)”, Trabalhos do Grupo de Estudos Arqueológicos do Porto, 2: 1-24.

Alves, L. B. y Reis, M. (2011): "Memoriais de pedra, símbolos de identidade: duas novas peças escultóricas de Cervos (Montalegre, Vila Real)”. En Vilaça, R. (ed.): Estelas e estátuas-menir: Da Pré à Protohistoria, Sabugal: Museu do Sabugal, pp. 187-216.

Armbruster, B. (1995): "O Colar de Sintra". En Jorge, S.O. (ed.): A Idade do Bronze em Portugal. Discursos de Poder, Lisboa: Museu Nacional de Arqueología: 103.

Baptista, A.m. (1995): “A Estátua-Menir Feminina da Ermida". En Jorge S.O. (ed.): A Idade do Bronze em Portugal. Discursos de poder. Lisboa: Museu Nacional de Arqueología: 27-28.

— (1985): "A estatua-menir da Ermida (Ponte da Barca, Portugal)", O Arqueologo Português, 4(3): 7-44.

Barceló, J.A. (1989): Arqueología, Lógica y Estadística: un análisis de las Estelas de la Edad del Bronce en la Península Ibérica. Tesis Doctoral inédita. Departamento de Historia de Societats Precapitalistes i Antropología Social. Universitat Autónoma de Barcelona. Barcelona.

Batata, C., Borges, N.; Correia, H. y Sousa, A. de (2008): Carta Arqueológica do Concelho de Vila Pouca de Aguiar, Vila Pouca de Aguiar. Ozecarus: Câmara Municipal e Ozecarus.

Berrocal Rangel, L. (1987): "El antropomorfo del Bodonal (Badajoz): Ensayo de interpretación de las estelas-guijarro y sus relaciones atlánticas", Arqueologia (Porto), 16: 83-94.

Bettencourt, A. (2005): "A estatuaria”. En Hidalgo Cuñarro, J.M. (ed.): Arte e cultura de Galicia e norte de Portugal (Arqueoloxía 1). Vigo: Nova Galicia Edicións: 166-177.

Brandherm, D. (1998): “Algunas consideraciones acerca de la espada de Guadalajara. ¿Un excepcional depósito desarticulado del Bronce Medio de la Meseta?”, Trabajos de Prehistoria, 55 (2), pp.177-184. 
— (2003): Die Dolche und Stabdolche der Steinkupfer- und älteren Bronzezeit auf der Iberischen Halbinsel. Stuttgart: Franz Steiner Verlag.

- (2007): Las Espadas del Bronce Final en la Península Ibérica y Baleares. Stuttgart: Franz Steiner Verlag.

Bueno Ramírez, P. (1990): "Statues-menhirs et stèles anthropomorphes de la Péninsule Ibérique", L'Anthropologie, 94 (1): 85-11.

- (1995): "Megalitismo, estatuas y estelas en España. En S. Casini, R. de Marinis y A. Pedrotti (eds.): Statue-stele e massi incisi nell'Europa dell'etá del Rame. Notizie Archeologiche Bergomensi, 3. Bergamo: Museo Archeologico di Bergamo: 77-130.

-; Balbín Behrmann, R. y Barroso Bermejo, R. (2005): "Hiérarchisation et métallurgie: statues armées dans la Péninsule Ibérique”, L’Anthropologie, 109 (4): 577-640.

Carvalho, P. S.; Gomes, L. F. y Franciasco, J.P.A. (1999): "A estátua-menir do Alto da Escrita (Tabuaço, Viseu)", Estudos Pré-Históricos, VII: 251-256.

Cardoso, J. L. (2002): Pré-História de Portugal. Lisboa: Ed. Verbo.

Celestino Pérez, S. (2001): Estelas de guerrero y estelas diademadas. La precolonización y formación del mundo tartésico. Barcelona: Bellaterra.

Comendador Rey, B.; Rodríguez Muñoz, V. y Manteiga Brea, A. (2011): “A estatua-menhir do Tameirón no contexto dos resultados de intervención arqueolóxica no Monte Urdiñeira e o seu contorno (A Gudiña-Riós, Ourense)". En Vilaça, R. (ed.): Estelas e estátuas-menir: Da Pré à Protohistoria. Sabugal: Museu do: 217-244.

Cruz, D. J. y Tomás Santos, A. (2011): “As estátuas-menires da serra da Nave (Moimenta da Beira, Viseu) no contexto da ocupação pré-histórica do Alto Paiva e da Beira Alta”. En Vilaça, R. (ed.): Estelas e estátuas-menir: Da Pré à Protohistoria. Sabugal: Museu do Sabugal: 117-142.

Delibes De Castro, G., Avello Álvarez, J.L.; Rojo Guerra, M.A. (1982): "Espadas del Bronce Antiguo y Medio halladas en la provincia de León”, Zephyrus, 34-35: 153-164.

Delibes de Castro, G. y Fernández Manzano, J. (1988): Armas y utensilios de bronce en la Prehistoria de las islas Baleares. Studia Archaeologica, 78. Valladolid: Universidad de Valladolid.

Díaz-Guardamino Uribe, M. (2010): Las estelas decoradas en la Prehistoria de la Península Ibérica. Madrid: Universidad Complutense de Madrid.

Fábrega Álvarez, P., Fonte, J. y González García, F.j. (2011): “Las sendas de la memoria. Sentido, espacio y reutilización de las estatuas-menhir en el noroeste de la Península Ibérica”, Trabajos de Prehistoria 68 (2): $313-330$.

Galán Domingo, E. (2000): "Las estelas del Suroeste entre el Atlántico y el Mediterráneo". En Actas del IV Congreso Internacional de Estudios Fenicios y Púnicos. Cádiz, 2 al 6 de Octubre de 1995, IV. Cádiz: Servicio de publicaciones de la Universidad de Cádiz: 1789-1797.

Gomes, M.V. (1994): A Necrópole de Alfarrobeira (S. Bartolomeu de Messines) e A Idade Do Bronze No Concelho De Silves. XELB: revista de arqueologia, arte, etnologia e história, 2. Silves: Museu Municipal de Arqueologia.

Gómez Ramos, P. (2001): "La espada de la perla: estudio de las empuñaduras de remaches con doble arco. Un unicum en la serie de armas europeas de la Edad del Bronce", Gladius, 21: 5-30.

Jorge, V. O. y Almeida, C. A. F. de (1980): “A Estátua-menir fálica de Chaves". Trabalhos do Grupo de Estudos Arqueológicos do Porto, 6: 1-24.

Jorge, V. O. y Jorge, S. O. (1990): "Statues-menhirs et stèles du Nord du Portugal”, Revista da Faculdade de Letras, II série, VII: 304-313.

— (1993): "Statues-menhirs et stèles du nord du Portugal". En Briard, J. y Duval, A. (eds.): Les representations humaines du Néolithique à L'Age du Fer. Actes du 115e congrès national des sociétés savantes. Avignon, 1990. París: Éd. du Comité des travaux historiques et scientifiques: 29-44.

Lopes, A.B.; Silva, A.C.F.; Parente, J.R. y Centeno, R.M.S. (1994): “A estátua-estela do Marco (Vreia de Jales, Vila Pouça de Aguiar)”, Portugalia, Nova Série, 15: 147-150.

Lopes, C. y Vilaça, R. (1998): "Peça do Bronze Final proveniente do 'Pé do Castelo' (Trindade, Beja)", Arquivo de Beja (serie 3), 7-8: 63-84.

López Plaza, S.; Sevillano San José, M.C. y Grande Del Río, R. (1996): "Estatua-menhir de Tremedal de Tormes (Salamanca)", Zephyrus, 49: 295-303.

Maluquer de Montes, J. (1971): "La estela de la edad del bronce de Preixana, Lérida". En Homenaje a Don José Esteban Uranga. Pamplona: Ed. Aranzadi: 475-481. 
Monteagudo, L. (1977): Die Beile auf der iberischen Halbinsel. Práhistorische Bronzefunde. Abteilung IX. Band 6. Munich: C.H. Beck'sche Verlagsbuchhandlung.

Olivier, L. (1999): "The Hochdorf "princely" grave and the question of the nature of ar-chaeological funerary assemblages". En Murray T. (ed.): Time and Archaeology. London: Routledge: 109-138.

Queiroga, F. (2003): War and Castros. New approaches to the northwestern Portuguese Iron Age. Oxford: British Archeological Report.

Rodríguez-Corral, J. (2015): "Las estatuas-menhir noroccidentales en contexto: conectividad y conexiones materiales durante el Bronce Tardío/Final”, Complutum, 26 (1): 153-172.

Ruiz-Gálvez Priego, M. (1984): La península Ibérica y sus relaciones con el círculo atlántico. Madrid: Universidad Complutense de Madrid.

Sanches, M.J. y Jorge, V.O. (1987): “A estátua-menir da Bouça (Mirandela)”. Arqueologia (Porto), 16: 78-82.

Sanches, M.J. (1995): "Estátua-menir da Bouça". En Jorge, S.O. (ed.): A Idade do Bronze em Portugal. Discursos de poder. Lisboa: Museu Nacional de Arqueología, p. 26.

Santoja Gómez, M. y Santoja Alonso, M. (1978): "La estatua-menhir de Valdefuentes de Sangusín", Boletín de la Asociación Española de Amigos de la Arqueología, 10: 19-24.

Santos, M.J. (2009): "Estelas diademadas: revisión de criterios de clasificación”, Herakleion, 2: 7-40.

Schuhmacher, T.X. (2002): "Some remarks on the origin and chronology of halberds in Europe", Oxford Journal of Archaeology, 21 (3): 263-288.

Silva, A. C. F. da (2007): A Cultura Castreja no Noroeste de Portugal. Paços de Ferreira: Câmara Municipal de Paços de Ferreira.

Taramelli, A. (1921): "Il Ripostiglio dei bronzi nuraghici di Monte Sa Idda, di Decimoputzu (Cagliari)", Monumenti Antichi dei Lincei, XXVII: 5-98.

Torres Ortíz, M. (2008): “Los tiempos de la precolonización”. En S. Celestino Pérez, R. Rafel y X.L. Armada (eds.): Contacto Cultural entre el Mediterráneo y el Atlántico (siglos XII-VIII ane). La precolonización a debate: Consejo Superior de Investigaciones Científicas. Madrid: 61-94.

Vilaça, R. (2004): "Ecos do mediterrâneo no Monte de São Martinho (Castelo Branco): a propósito de um artefacto do Bronze Final". Estudos Castelo Branco, Nova Serie 3: 5-18.

—.; Cruz, D. J.; Santos, A. T. y Marques, J. N. (2001): “A estátua-menir de 'Ataúdes' (Figueira de Castelo Rodrigo, Guarda) no seu contexto regional”. Estudos Pré-Históricos, 9: 69-82. 